\title{
EXPERIMENTAL INVESTIGATION ON CERIUM OXIDE NANOPARTICLES WITH ALUMINA CATALYTIC CONVERTER TO INCREASE EMISSION CONVERSION EFFICIENCY IN AUTOMOBILES
}

\author{
S. Sendilvelan ${ }^{1 *}$, K. Bhaskar ${ }^{2}$ and S. Nallusamy ${ }^{1}$ \\ ${ }^{1}$ Department of Mechanical Engineering, Dr. M.G.R. Educational and Research Institute, \\ University, Chennai-600095, (Tamilnadu) India \\ ${ }^{2}$ Department of Automobile Engineering, Rajalakshmi Engineering College, Thandalam, \\ Chennai-602105, (Tamilnadu) India \\ *E-mail : sendilvelan.mech@drmgrdu.ac.in
}

\begin{abstract}
The increasing use of diesel passenger cars has led to considerable work in the methods resulting in the reduction of particulate emissions. Interest is centered on reduction of emission in diesel engines from the new methods and technologies, diesel particulate filter, fuel additives for particulate matter. The objective of this research is to calculate various emission factors in diesel engine using cerium oxide nanoparticles. The experimental result reveals that the influence of cerium oxide in the form of nanoparticles for oxides of nitrogen, hydrocarbon and carbon monoxide levels in a diesel engine. The cerium oxide increase the conversion rate due to the oxygen content for the oxidation process of carbon monoxide and hydrocarbon in the catalytic converter. It was also observed that the cerium nanoparticles reduce the oxides of nitrogen effectively. The catalytic behavior in the higher temperature range enhanced the conversion of hydrocarbon and oxides of nitrogen, cerium nitrate precursor gives greater activity. Above $250^{\circ} \mathrm{C}$, the conversion of $\mathrm{HC}, \mathrm{NO}_{\mathrm{x}}$ increased and reached up to $98 \%$ conversion, when the temperature increased to $440^{\circ} \mathrm{C}$.
\end{abstract}

Keywords: Automobile, Alumina, Cerium Oxide, Catalytic Converter, Nanoparticles

(C) RASĀYAN. All rights reserved

\section{INTRODUCTION}

Burning of fuel or burning of anything releases harmful and toxic gases, particulate matter, smoke, etc. into the atmosphere. The major portion of the pollutants degrading the atmosphere is from transport sector and power plants. In transport sector, the engine, especially the diesel engine emissions cause serious environmental and human discomforts on global scale ${ }^{1}$. Inhaling of this diesel polluted atmospheric air, which is rich in smoke and nitrous oxides $\left(\mathrm{NO}_{\mathrm{x}}\right)$ may result in serious respiratory cardiovascular bronchitis, hemorrhages, cancer etc. on human beings ${ }^{2}$. Thermally stable, increased surface area $\left(\mathrm{ex}>100 \mathrm{~m}^{2} / \mathrm{g}\right)$ alumina is used in the Nano sized wash coat particles of noble metals for the automobile exhaust ${ }^{3,4}$. Ceric oxide $\left(\mathrm{CeO}_{2}\right)$ also called as ceria impregnated into the alumina particles and acted as carrier for the platinum and/or palladium and rhodium. Initially, ceria was used about 2 to 3 percent, now it is being used in larger proportion say about 20 to 40 percent by weight of the carrier ${ }^{5,6}$. In diesel engine the combustion reactants come into contact with a surface of catalytic converter and converted to harmless constituents ${ }^{7,8}$. These metal nanoparticles are highly reactive, which can make a big impact on the conversion efficiency of catalytic converters 9 .

Given below are the equations for surface area and volume:

$$
\begin{aligned}
& \text { Surface Area of Each Parcle: SA }(r)=A=4 \pi r^{2} \\
& \text { Volume of Each Parcle: } v(r)=\frac{4}{3} \pi r^{3}
\end{aligned}
$$


Total surface area as a function of particle radius (r), assuming a constant total volume $\mathrm{V}$ and number of particles

$$
\begin{aligned}
& \frac{\text { Total Surface Area TSA }(r)}{\text { Total Volume V }}=\frac{N \cdot S A(r)}{N \cdot v(r)}=\frac{N \cdot \pi r^{2}}{N \cdot \frac{4}{3} \pi r^{3}} \\
& \text { Total Surface Area TSA }(r)=\frac{3 V}{r}
\end{aligned}
$$

In the present work, it was decided to increase the surface area and increase the emission reduction with cerium oxide nanoparticle added with alumina in a new designed catalytic converter.

\section{Shape and Dimensions of canister}

\section{EXPERIMENTAL}

It was reported in the literatures that for optimizing catalyst applied surface area, catalyst volume must be 1.5 to 2 times the engine displacement ${ }^{10}$. The displacement volume of the diesel engine selected for this present investigation is $1106.28 \mathrm{~cm}^{3}$. The total volume of catalyst used in the (revised) model is $1711 \mathrm{~cm}^{3}$ i.e. the sum of volumes of coated wire meshes and solid catalytic beads. The modified canister volume is $5924 \mathrm{~cm}^{3}$, the catalyst occupies $1711 \mathrm{~cm}^{3}$ only and the remaining volume inside the canister is used for the exhaust gas to flow to reduce the back pressure, conforming effective diesel oxidation catalyst (DOC) and selective catalytic reduction (SCR) systems ${ }^{11,12}$.

\section{Construction of Canister}

The exhaust canister comprises two compartments, namely DOC catalyst and another SCR system ${ }^{13}$. DOC filled with steel wire meshes are placed vertically with their surface being parallel to the flow of gas. Sufficient gaps are provided amongst these bundles of wire meshes as shown in Figure-1. The wire meshes provide zigzag path for the gas flow to obtain efficient contact with wire meshes which enhances better filtration as well as better catalytic action in reducing both particulate matter and oxides of Nitrogen ${ }^{14}$. A set of compartments I and II which are loaded with catalytic beads and different grid size steel wire meshes are shown in Figure-2. The net weight of the canister filled with two compartments is around $5.2 \mathrm{~kg}$.

\section{Selection of Catalyst}

The important criteria for the selection of catalyst material are higher NOx and PM conversion efficiency, withstanding higher temperatures, avoidance of harmful by-products, cost and its availability ${ }^{15}$.

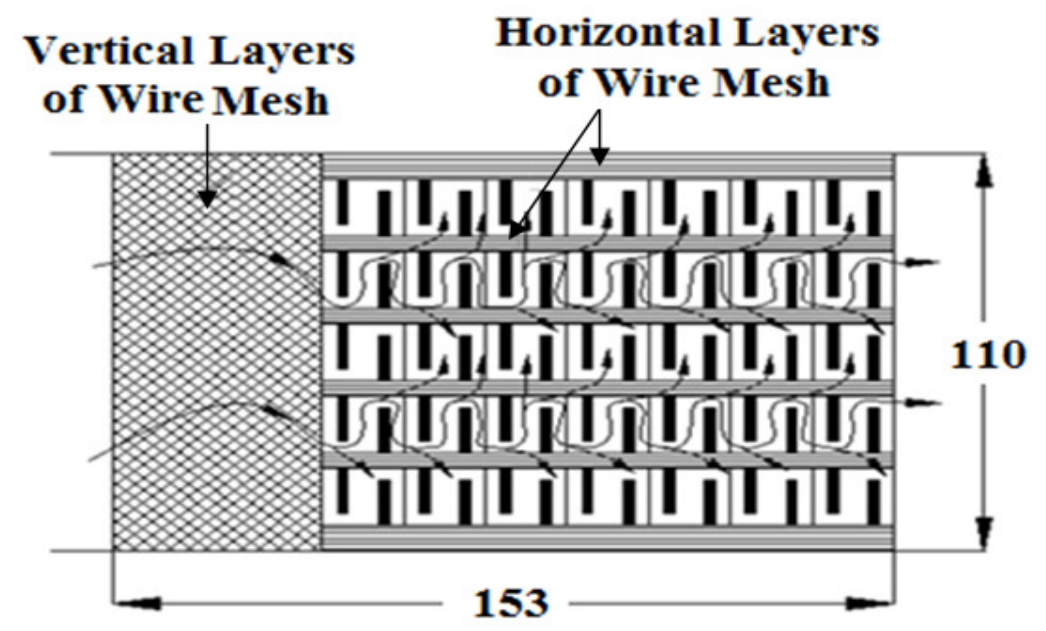

Fig.-1: Compartments Filled with Catalyst and Filter Materials. 


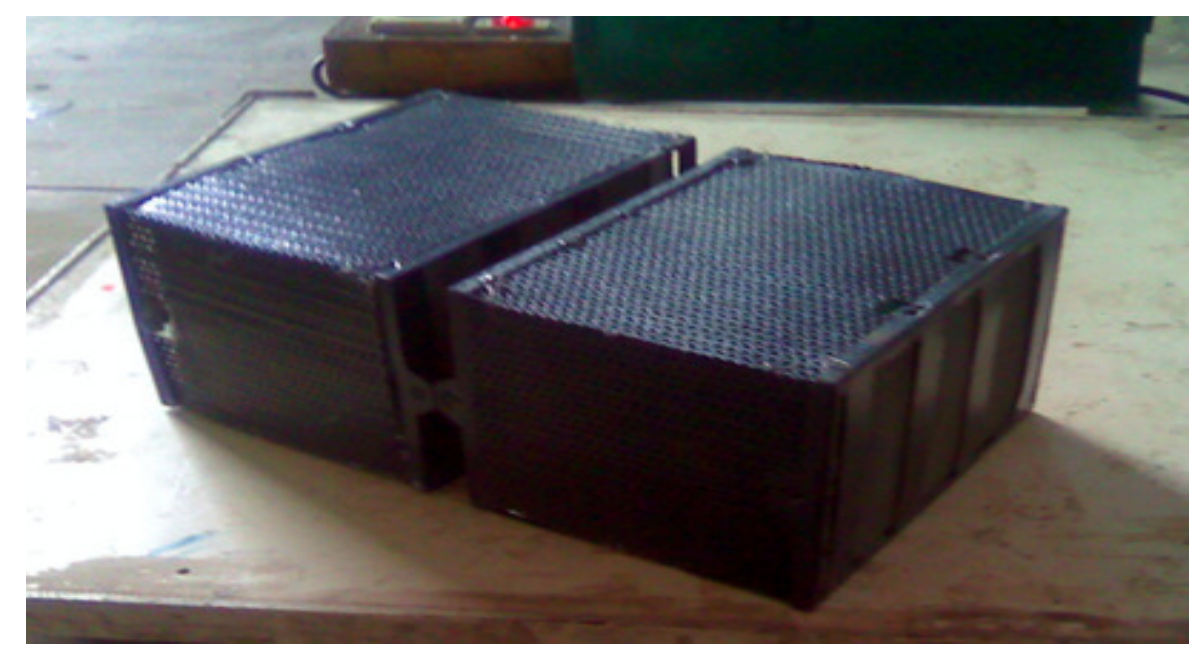

Fig.-2: Newly Developed Exhaust Canisters.

Alumina can withstand high temperatures, and a high surface area cerium oxide is an important component of catalyst composition, three methods are used to prepare cerium oxide. Each of the wash coats was prepared to contain gamma alumina and ceria in the proportion of 72 weight percent alumina and 28 weight percent ceria. All the ceria content of the wash coat came from cerium carbonate $\mathrm{Ce}\left(\mathrm{CO}_{3}\right)_{3}$ which was added into the mill and calcined as a part of the wash coat, followed by impregnation with platinum and rhodium. A second wash coat was cerium nitrate, $\mathrm{Ce}\left(\mathrm{NO}_{3}\right)_{3}$ and third comparison wash coat material with high surface area ceric in conjunction with the gamma alumina.

\section{Development of Filter Medium}

Selection of Filter Medium: The purpose of providing filter medium inside the canister is to filter the solid particle of particulate matter that is present in the diesel engine exhaust emission. The accumulation of PM on the surface of filter medium causes the pressure drop inside the canister. This results in increased back pressure having an adverse effect on maximum power of the engine and fuel economy. Wire mesh of a coarse category with $1.96 \mathrm{~mm}$ gap (100 CPSI) was selected along with medium category, wire mesh with $1.61 \mathrm{~mm}$ gap (144 CPSI). Wire mesh with $1.01 \mathrm{~mm}$ gap (324 CPSI) categorized as fine and wire mesh with $0.65 \mathrm{~mm}$ (576 CPSI) gap which is very fine category were also selected. Steel wire mesh were stacked one over the other makes the flow as turbulent flow. Thus, the laminar flow of exhaust gas is interrupted, thereby creating turbulence for improved mass transfer. This flow increased the travel length and contact time so that more amount of DOC and SCR catalytic actions can take place and hence more PM and NOx reductions are achievable. Next to the vertical wire mesh bundles there is a window plate having $14 \mathrm{~mm}$ wide openings of $14 \mathrm{~mm}$ size at $21 \mathrm{~mm}$ pitches, i.e. $7 \mathrm{~mm}$ width metal portion of window plate is placed just opposite to the $6 \mathrm{~mm}$ gap available in between wire mesh bundles. This $7 \mathrm{~mm}$ width metal portion prevents the gas flowing straight and diverts it to pass through the wire meshes, which helps better DPF and DOC actions. The diverted gas will leave out through $14 \mathrm{~mm}$ opening of the window plate.

\section{Analysis of Exhaust Gas Velocity}

Diameter of piston

Stroke length,

Speed,

Diameter of valve port,

Valve lift,

No. of inlet \& outlet valve per cylinder, $\mathrm{m}=1$ each

$$
\begin{aligned}
& \mathrm{D}=80 \mathrm{~mm} \\
& \mathrm{~L}=110 \mathrm{~mm} \\
& \mathrm{~N}=1500 \mathrm{rpm} \\
& \mathrm{d}=20 \mathrm{~mm} \\
& \mathrm{l}=9 \mathrm{~mm}
\end{aligned}
$$


Valve is opened by $14^{\circ}$ earlier $\&$ closed $48^{\circ}$ later. i.e. $\lambda=180+14+48=242^{\circ}$

Volume of gas flowing through the valves $=\frac{\pi}{4} \mathrm{D}^{2} \mathrm{~L}$

Time for the valve opening $\quad=\frac{60}{\mathrm{~N}} \times \frac{\lambda}{360}$ seconds

The average volume rate of flow/sec

$$
=\frac{\pi}{4} \mathrm{D}^{2} \mathrm{~L} \times \frac{360 \mathrm{~N}}{60 \lambda}=\frac{3 \pi \mathrm{D}^{2} \mathrm{LN}}{2 \lambda}=\frac{1.5 \pi \mathrm{D}^{2} \mathrm{LN}}{\lambda}
$$

Area of flow in the valves $=0.6 \times \pi \mathrm{dl} \times \mathrm{m}$ (Where the average discharge co-efficient is assumed as 0.6)

$$
\begin{gathered}
\text { Velocity of flow }=\frac{\text { Volume } / \mathrm{sec}}{\text { area }}=\frac{1.5\left(\pi \mathrm{D}^{2} \mathrm{LN}\right)}{\lambda(0.6 \pi \mathrm{dlm})}=\frac{1.5}{0.6} \times \frac{\mathrm{D}^{2} \mathrm{LN}}{\mathrm{dlm} \lambda} \\
=\frac{2.5 \times(0.08)^{2} \times 0.11 \times 1500}{0.02 \times 0.009 \times 1 \times 242}=60.60606 \mathrm{~m} / \mathrm{sec} .
\end{gathered}
$$

Velocity of exhaust gas flow $=60.61 \mathrm{~m} / \mathrm{sec}$

\section{Regeneration Period}

$$
1 \mathrm{kWh}=1.341 \mathrm{hp}: \therefore 1 \mathrm{hp}=\frac{1}{1.341} \mathrm{kWh}
$$

On an average $5.2 \mathrm{hp}$ of power and $45 \mathrm{~km} / \mathrm{h}$ of speed are assumed.

$$
\mathrm{kWh} \text { equivalent of the assumed hp of } 5.2=\frac{1}{1.341} \times 5.2=3.877 \mathrm{kWh}
$$

This means $3.877 \mathrm{kWh}$ energy is consumed to cover $45 \mathrm{~km}$ distance in one hour time. The distance covered while spending,

$$
1 \mathrm{kWh} \text { energy }=\frac{45}{3.877}=11.607 \mathrm{~km}
$$

i.e. for every $11.607 \mathrm{~km}$ distance covered, $1 \mathrm{kWh}$ energy is consumed.

For an average aged engine, when $1 \mathrm{kWh}$ energy is consumed, a maximum of 0.02 gram of particulate matter is permitted to accumulate as per Euro IV and Euro V norms.

$$
\text { i.e. }=\frac{0.02}{11.607} \mathrm{~g} \text { of particulate matter is deposited for every, one } \mathrm{km} \text { of the distance covered. }
$$

i.e. $1.7231 \times 10^{-3} \mathrm{~g}$ of particulate matter accumulation is permitted per $\mathrm{km}$ of distance covered.

\section{Compartment I}

Void volume in the first compartment $=597.368 \mathrm{~cm}^{3}$

PM of $10 \%$ deposit (assumed) $\quad=597.368 \times 0.1$

$$
=59.7368 \mathrm{~cm}^{3}
$$

\section{Compartment II:}

$\begin{array}{ll}\text { Void volume in the first compartment } & =557.357 \mathrm{~cm}^{3} \\ \text { PM of 10\% deposit (assumed) } & =557.354 \times 0.1\end{array}$

$$
=55.735 \mathrm{~cm}^{3}
$$

Volume of beads $=$ Surface area $\mathrm{x}$ Thickness of PM deposit

50 microns of PM deposit is assumed on beads body surface

$$
\begin{aligned}
& =(14.953 \times 644) \times 0.005 \mathrm{~cm} \\
& =48.1486 \mathrm{~cm}^{3}
\end{aligned}
$$

Total volume of PM deposit $=(9)+(10)+(11)$ 
Bulk density of PM

$\therefore$ Mass of PM deposit

$$
\begin{gathered}
=59.7368+55.735+48.1486 \\
=168.6208 \mathrm{~cm}^{3} \\
=0.075 \mathrm{~g} / \mathrm{cm}^{3} \\
=168.6208 \times 0.075 \\
=12.2715 \mathrm{~g}
\end{gathered}
$$

i.e. when $10 \%$ volume of void space is filled with PM deposit on wire meshes and 50 microns of PM deposit on catalytic beads, the total mass of PM deposit $=\mathbf{1 2 . 2 7 1 5} \mathrm{g}$. This means during this $12.2715 \mathrm{~g}$ of PM is getting accumulated, the distance covered,

$$
=\frac{12.2715}{1.7231 \times 10^{-3}}=7121.875 \mathrm{~km}
$$

From the observed results, it was concluded that for every $7000 \mathrm{~km}$ of engine run, regeneration (i.e. cleaning of canister) is a must.

\section{Catalytic performances}

\section{RESULTS AND DISCUSSION}

Figures-3, 4 and 5 present the conversion of carbon monoxide, hydrocarbon and $\mathrm{NO}_{\mathrm{x}}$ under stoichiometric conditions $(\lambda=1)$ over fresh cerium oxide using three wash coat methods, the precursor of the ceria was cerium carbonate, the precursor of the ceria was cerium nitrate, and cerium oxide gamma alumina catalysts.

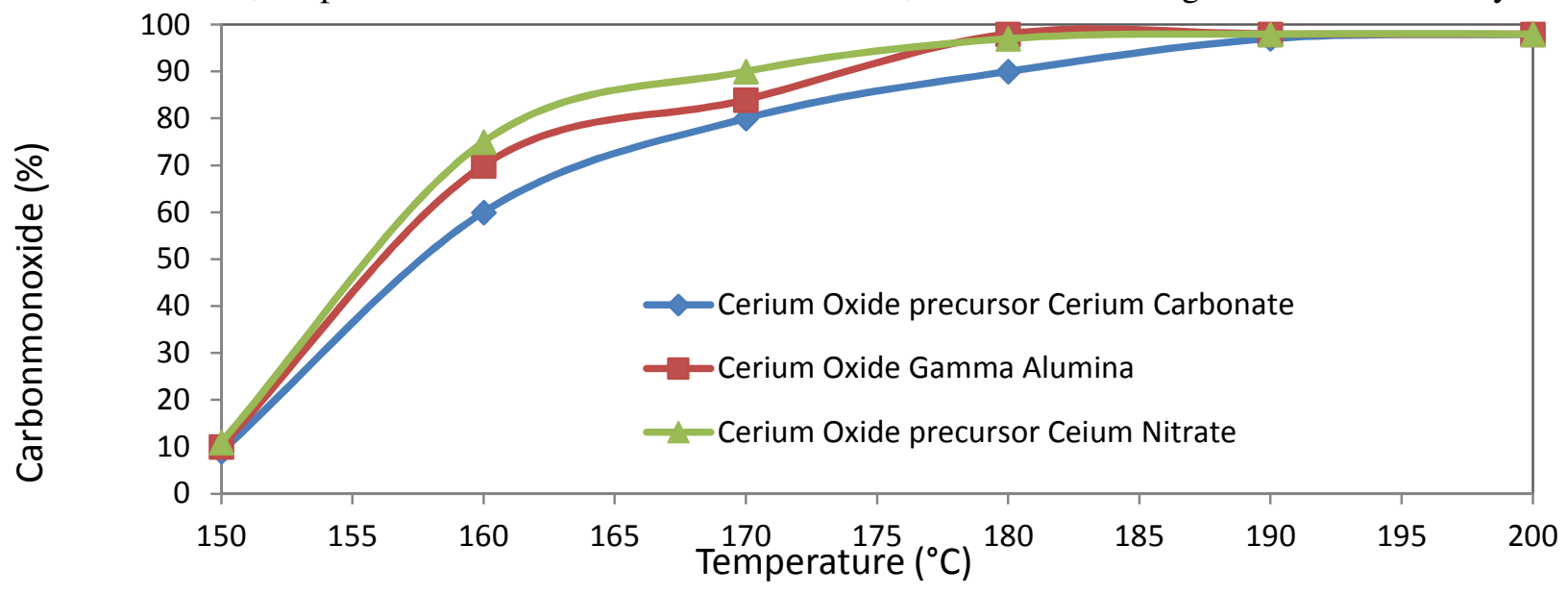

Fig.-3: Variation of Carbon monoxide Conversion Efficiency with Temperature.

The temperature maintained as 150 to $200^{\circ} \mathrm{C}, \mathrm{HC}$ and $\mathrm{NO}_{x}$ did not take part in the reaction, while the reactions of $\mathrm{CO}$ were predominated ${ }^{16}$. The catalytic behavior in the higher temperature range enhanced the conversion of hydrocarbon and oxides of nitrogen, cerium nitrate precursor gives greater activity. Above $250^{\circ} \mathrm{C}$, the conversion of $\mathrm{HC}, \mathrm{NO}_{\mathrm{x}}$ increased when the temperature increased.

These results show that the presence of ceria increases the catalytic activities with HC and NOx removal. Thus, the cerium oxide precursor of cerium nitrate catalyst also exhibit better activity than the other catalysts. The experimental tests show that cerium nanoparticles can be effectively used as an additive in the catalytic converter to improve the exhaust emission reduction.

\section{CONCLUSION}

In the present work, it was proposed to increase the surface area of catalyst and to increase the emission reduction with cerium oxide nanoparticle added with the alumina in a new designed catalytic converter. Based on the experimental analysis the following observations were made.The experimental results reveal that there is a reduction of $\mathrm{CO}, \mathrm{HC}$ and oxides of nitrogen using cerium oxide nanoparticle in well-designed metal monolith. 
The cerium oxides act as a Nano particle to provide oxygen for the oxidation of $\mathrm{CO}$ and $\mathrm{HC}$ in the catalytic converter.

It was also observed that the cerium nitrate catalytic behavior in the higher temperature range was enhancing the conversion of HC and NOx.

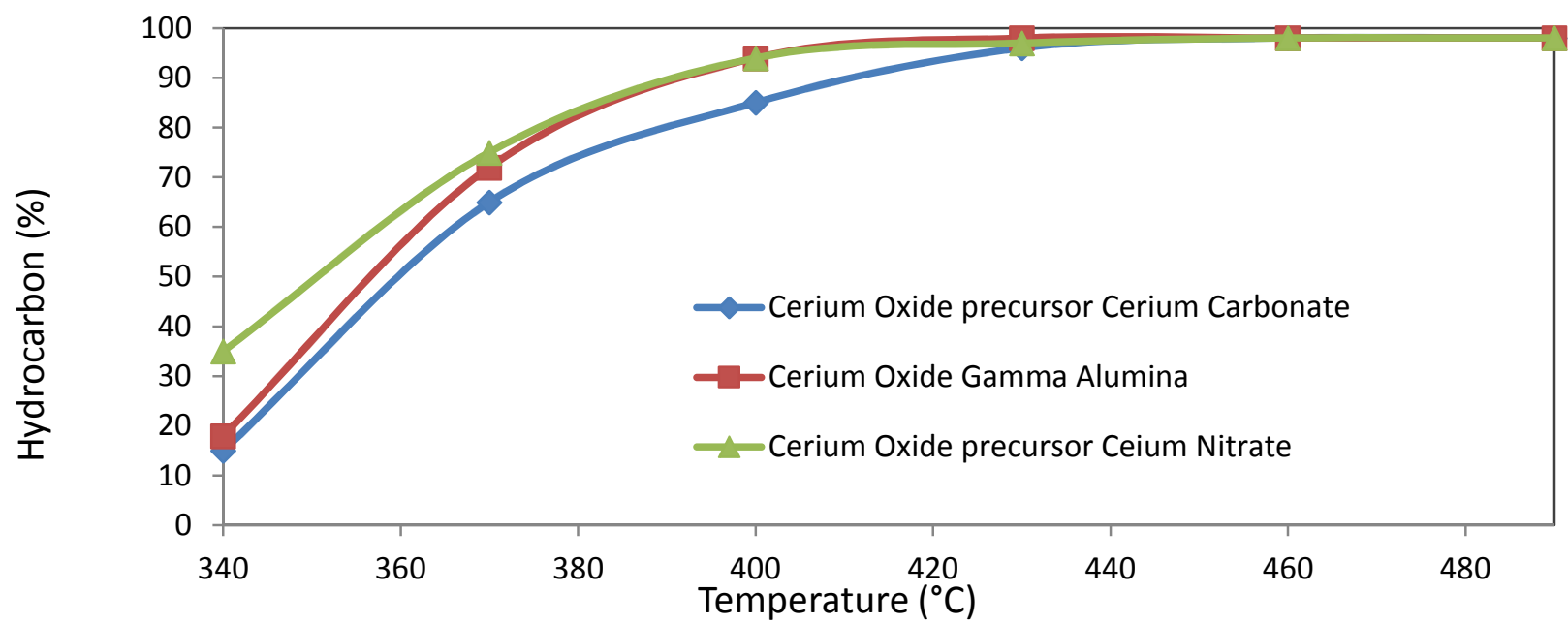

Fig.-4: Variation of Hydrocarbon Conversion Efficiency with Temperature.

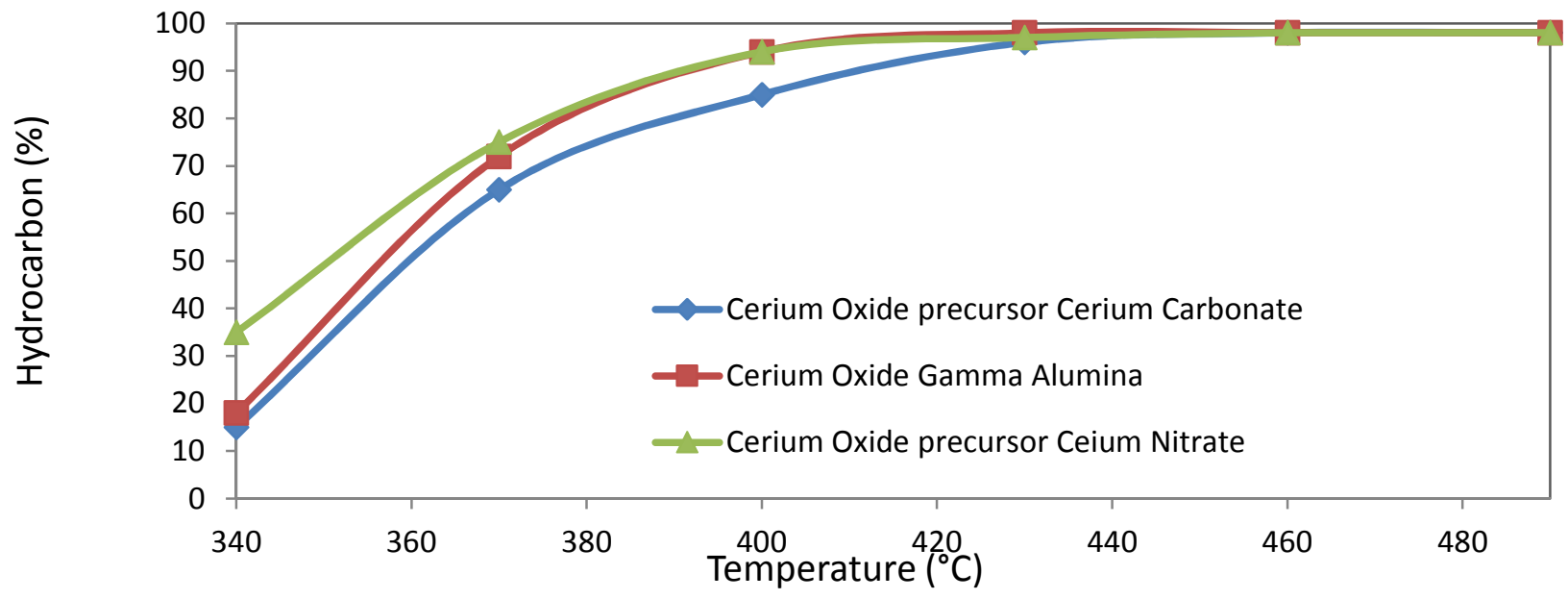

Fig.-5: Variation of Oxides of Nitrogen Conversion Efficiency with Temperature.

\section{REFERENCES}

1. I.A. Reşitołlu, K. Altinişik, A. Keskin, Clean Technologies and Environmental Policy,17(1) 15(2014).

2. S. Saito, R. Shinozaki, A. Suzuki, H. Jyoutaki, Y. Takeda, SAE paper, 724, 1 (2003).

3. F. Bonet, S. Grugeon, R. Herrera Urbina, K. Tekaia-Elhsissen, J.M. Tarascon, Solid State Sciences, 4 (5), 665 (2002).

4. C.S. Raj, S. Arul, S. Sendilvelan, C.G. Saravanan, Energy Sources Part A-Recovery Utilization and Environmental Effects, 32 (17), 1603 (2010).

5. L.F. Liotta, A. Longo, G. Pantaleo, G. Di Carlo, A. Martorana, S. Cimino, G. Russo, G. Deganello, Applied Catalysis B: Environmental, 90 (3-4), 470 (2009).

6. S. Sendilvelan, K. Rajan, Rasayan Journal of Chemistry, 10 (1), 190 (2017).

7. Pl. S., M.; Kumar, M. S.; Subramanian, S. SAE Technical Papers 2011. 
RASĀYAN J. Chem.

Vol. 10 | No. 2 |454 - 460 | April - June | 2017

8. S. Sendilvelan, K. Jeyachandran, K. Bhaskar, American Society of Mechanical Engineers, Internal Combustion Engine Division (Publication) ICE, 36. (2001).

9. N. Nithyanandan, S. Sendilvelan, K. Bhaskar, N. Balaji, S. Mohanamurugan, International Journal of Applied Engineering Research, 5 (3), 441 (2010).

10. P.M. More, D.L. Nguyen, P. Granger, C. Dujardin, M.K. Dongare, S.B. Umbarkar, Applied Catalysis B: Environmental, 174-175, 145 (2015).

11. M. Colombo, I. Nova, E. Tronconi, In Catalysis Today, 151, 223 (2010).

12. T.C. Watling, M.R. Ravenscroft, G. Avery, In Catalysis Today; 188, 32 (2012).

13. S. Sendilvelan, K. Bhaskar, Rasayan Journal of Chemistry, 10 (1), 111 (2017).

14. S. Sendilvelan, K. Bhaskar, Rasayan Journal of Chemistry, 9 (4), 692 (2016).

15. B.M. Shakya, M.P. Harold, V. Balakotaiah, Chemical Engineering Journal, 237, 109 (2004).

16. J.R. Theis, E. Gulari, Applied Catalysis B: Environmental, 75 (1-2), 39 (2007).

[RJC-1685/2017] 